Jurnal PG-PAUD Trunojoyo : Jurnal Pendidikan dan Pembelajaran Anak Usia Dini, Volume 8, Nomor 1, April 2021 hal 8 - 14, ISSN : 2528-3553 (online), ISSN: 2407-4454 (print)

\title{
PERAN GURU DALAM PENERAPAN SEKOLAH RAMAH ANAK DI TK YKK 1 BANGKALAN
}

\author{
Mega Wulan Sari ${ }^{1}$ \\ Dwi Nurhayati Adhani² \\ Muhammad Busyro Karim ${ }^{3}$ \\ ${ }^{1,2,3}$ Program Studi Pendidikan Guru Pendidikan Anak Usia Dini, Universitas Trunojoyo Madura \\ Email:mega90011@gmail.com, dwinadhani@gmail.com, busyrokarim.dz@gmail.com
}

Received (Januari), Accepted (Maret), Published (April)

\begin{abstract}
The Role of Teachers in the Implementation of Child Friendly Schools in TK YKK 1 Bangkalan. Fulfilling the rights and protection of early childhood is important because it is the key to the success of children's growth, development and welfare.This study aims to describe the role of teachers in implementing child-friendly school programs in TK YKK 1 Bangkalan. The description is related to the teacher's role in learning and implementing child-friendly school programs. This research uses descriptive qualitative method. Data collection techniques in this study used observation, interviews and documentation. Checking the validity of the data uses triangulation of sources and techniques. The results of this study indicate that the teacher's role in implementing child-friendly schools includes facilitators, mentors, and motivators. The application of child-friendly schools in TK YKK 1 Bangkalan include non-discrimination, fun and safe learning, actively involving children in learning activities, and providing good facilities for children.
\end{abstract}

Keywords: role of teachers, early childhood, friendly school programs

\begin{abstract}
Abstrak: Peran Guru dalam Penerapan Sekolah Ramah Anak di TK YKK 1 Bangkalan. Pemenuhan hak dan perlindungan pada anak usia dini menjadi penting karena sebagai kunci keberhasilan pertumbuhan, perkembangan, serta kesejahteraan anak. Penelitian ini bertujuan untuk mendeskripsikan peranan guru dalam penerapan program sekolah ramah anak di TK YKK 1 Bangkalan. Deskripsi tersebut terkait dengan peranan guru dalam pembelajaran dan penerapan program sekolah ramah anak. Penelitian ini menggunakan metode kualitatif deskriptif. Pennelitian ini mengguankan pengumpulan data yang terdiri dari observasi, wawancara, dan adanya dokumentasi lapangan. Untuk keabsahan data penelitian ini menggunakan triangulasi sumber dan teknik. Penelitian ini menghasilkan yaotu suatu peran dari guru sebagai fasilitator, pembimbing, dan motivator. Penerapan sekolah ramah anak di TK YKK 1 Bangkalan antara lain tidak melakukan diskriminasi, melakukan pembelajaran yang menyenangkan dan aman, melibatkan anak secara aktif dalam kegiatan pembelajaran, serta memberikan fasilitas yang baik untuk anak.
\end{abstract}

Kata Kunci : peran guru, anak usia dini, sekolah ramah anak 
Jurnal PG-PAUD Trunojoyo : Jurnal Pendidikan dan Pembelajaran Anak Usia Dini, Volume 8, Nomor 1, April 2021 hal 8 - 14, ISSN : 2528-3553 (online), ISSN: 2407-4454 (print)

\section{PENDAHULUAN}

Pendidikan merupakan hak asasi setiap warga negara, zaman teknologi ini maka pendidikan merupakan kebutuhan yang utama bagi suatu warga negara .Seperti yang tertera dalam Undang Undang No. 20 Tahun 2003 tentang Sistem Pendidikan Nasional Pasal 1 Ayat 1 dinyatakan bahwa pendidikan adalah usaha sadar dan terencana untuk mewujudkan suasana belajar dan proses pembelajaran agar peserta didik secara aktif mengembangkan potensi dirinya untuk memiliki kekuatan spiritual keagamaan, akhlak mulia, serta keterampilan yang diperlukan untuk dirinya, masyarakat, bangsa dan Negara (KPAI, 2016). Armai Arief dalam Muhammad Fadillah menjelaskan menurut bahasa Yunani, pedagogi yang memiliki arti bahwa seorang individu yang memiliki tugas sebagai pendidik dan pembimbing seorang anak. Arti yang lebih spesifik adalah sebuah pendidikan sebagai kegiatan untuk membimbing yang dilakukan kepada anak-anak untuk membantu pertumbuhannya secara jasmani maupun rohani, yang dapat menunjang perannya kelak di masyarakat (Fadlillah, 2012). Berdasarkan penjelasan diatas maka suatu pendidikan adalah aktivitas membimbing dan melakukan pengembangan secara terarah kepada anak dengan target yang jelas. Aktivitas bimbingan dapat dilakukan dengan terstruktur dan memiliki tujuan dari orang dewasa kepada anak.

Pendidikan dapat terlaksana jika ada pendidik (guru) dan peserta didik (anak) di dalamnya. Guru adalah profesi sebagai tenaga kependidikan yang memberikan pengabdian dalam penyelenggaraan pendidikan. Menurut beberapa tokoh tentang definisi guru memiliki beberapa perspektif, diantaranya menurut Ngalim Purwanto menuturkan bahwa guru adalah seorang individu yang bersedia memberikan ilmu yang dimiliki untuk dipelajari oleh orang lain, serta guru adalah seorang yang bersedia untuk memberikan waktu, energi serta kerja keras untuk mengabdi pada Negara dan merupakan individu yang berjasa pada Negara dan masyarakat (Husain, 2017). Menurut tokoh yang lain yaitu Piet A. Sahertian definisi dari guru adalah seorang yang memiliki tuntutan untuk melakukan suatu amal soleh dengan memberikan keilmuan yang telah dikuasai dan dimiliki. Guru secara langsung memiliki tanggung jawab yang besar kepada peserta didik, tidak hanya pada saat proses belajar mengajar, namun saat pembelajaran di luar kelas (Naim, 2016). Berdasarkan penjelasan diatas maka dapat ditarik kesimpulan bahwa guru adalah tenaga pendidik yang memiliki tanggungjawab kepada anak didiknya untuk memberikan ilmunya melalui proses pembelajaran.

Profesi pendidik dan tenaga kependidikan dituntut untuk dapat melakukan proses pembelajaran dengan cara memberikan fasilitas peserta didik untuk mengaplikasikan perilaku terpelajar. Bentuk perilaku terpelajar yang diperlihatkan adalah seperti dalam mencapai suatu prestasi akademik, memperlihatkan suatu perilaku yang sesuai dengan etika/moral, menunjukkan akhlak mulia, adanya motivasi belajar yang tinggi, adanya kemampuan untuk lebih kreatif, menerapkan perilaku disiplin, adanya tanggung jawab, dan memperlihaktkan suatu karakter sebagai warga negara Indonesia yang baik. Sekolah seharusnya menjadi satuan pendidikan yang memberikan kenyaman pada peserta didik, dengan memperlihatkan sekolah yang anti pada tindak kekerasan yang dilakukan oleh teman, kakak kelas, maupun guru dan tenaga pendidik yang lain, agar anak merasa nyaman, aman, dan menyenangkan saat berada di sekolah. Beberapa tahun terakhir dunia pendidikan memiliki perkembangan seperti sekolah yang memiliki ciri khas seperti sekolah terpadu, sekolah bertaraf internasional, sekolah berkarakter yang tujuannya untuk mewujudkan pendidikan yang sesuai dengan jaman. Untuk saat ini, program yang sedang diterapkan di berbagai 
Jurnal PG-PAUD Trunojoyo : Jurnal Pendidikan dan Pembelajaran Anak Usia Dini, Volume 8, Nomor 1, April 2021 hal 8 - 14, ISSN : 2528-3553 (online), ISSN: 2407-4454 (print)

sekolah ialah program Sekolah Ramah Anak yang biasa disebut SRA.

Sekolah Ramah Anak adalah suatu sekolah yang bertujuan untuk memenuhi hak-hak anak serta menjunjung tinggi perlindungan anak dengan tujuan yang terencana dan bertanggung jawab (KPAI, 2016). Sekolah Ramah Anak dapat diartikan dengan sekolah yang dapat mengenali potensi anak dan memberikan fasilitas untuk mengembangkan potensi yang dimiliki. Guru berperan penting dalam menciptakan sekolah yang ramah anak, karena guru memiliki berbagai peran yang dapat dimainkan dan diterapkan kepada anak terutama di dalam kelas, yaitu guru sebagai sumber dari informasi, menjadi seorang fasilitator, menjadi seorang pengelola, demonstrator, motivator, yang mengevaluasi, dan menjadi pembimbing (Sanjaya, 2016). Peran-peran tersebut dapat menjadi salah satu dari berbagai cara untuk mewujudkan pembelajaran yang ramah anak guna mewujudkan sekolah ramah anak. Adapun prinsip utama perlindungan anak antara lain: tanpa kekerasan, tanpa diskriminasi, adanya hak tumbuh dan berkembang serta adanya penghargaan terhadap pendapat anak.

Berdasarkan Pedoman Pendidikan Ramah Anak, bentuk suatu model sekolah ramah anak yang dikembangkan oleh UNICEF yaitu dengan menyediakan konsep ramah pada anak dengan sebuah ideologi dengan bentuk sekolah yang aman, memiliki perlindungan, adanya pendidik yang sudah terlatih, dan memiliki sumber daya yang mendukung. Adapun prinsip dasar yang digunakan dalam Sekolah Ramah Anak diperoleh dari Konvernsi Hak Anak atau Convention on the Right of the Child (CRC) yang dikeluarkan oleh Perserikatan Bangsa-Bangsa (PBB). Prinsip ini memiliki konsep bahwa adanya panduan dalam mengelola suatu sekolah dan kelas agar peserta didik dapat memiliki hak yang sesuai serta mendapatkan kualitas pendidikan yang sesuai dengan hak-hak yang diperlukan anak.

Salah satu lingkungan pendidikan yaitu sekolah sebaiknya menjadi tempat yang aman bagi anak, jauh dari tindakan diskriminatif dan tindak kekerasan yang dapat melanggar hak-hak anak. Seorang anak perlu mendapatkan perlindungan dimana pun dia berada, tak terkecuali di sekolah. Disebutkan dalam Undang-Undang Nomor 23 Tahun 2002 tentang Perlindungan Anak Pasal 54 Ayat 1 "Anak di dalam dan di lingkungan sekolah wajib dilindungi dari tindakan yang dilakukan oleh guru, pengelola sekolah, atau teman temannya di dalam sekolah yang bersangkutan atau lembaga pendidikan lainnya" (Aqib, 2008). Oleh sebab itu, sekolah memiliki kewajiban untuk melindungi serta mendidik anak dengan baik, aman dan nyaman. Meskipun telah jelas mengenai sekolah aman dan nyaman, namun kenyataannya masih banyak tindakan-tindakan kekerasan maupun diskriminasi pada anak yang terjadi baik di lingkungan sekolah, lingkungan rumah maupun lingkungan masyarakat.

Radar Madura menulis bahwa kasus kekerasan yang terjadi terhadap anak dan perempuan di Kabupaten Bangkalan masih tergolong tinggi. Di awal bulan September 2018, kasus kekerasan tercatat sebanyak 15 kasus, yaitu pemerkosaan, adanya pencabulan, penculikan, dan juga kekerasan psikis. Kepala Perwakilan UNICEF Wilayah Jawa Arie Rukmantara menyayangkan tingginya kasus kekerasan khususnya pada anak-anak. Menurutnya, siklus kekerasan harus diputus, sebab berdampak buruk bagi masa depan anak oleh karenanya, orang tua harus diberi pemahaman bahwa mendidik anak bukan dengan kekerasan. Arie mengaku, UNICEF sudah bekerjasama dengan pemerintah untuk menyelesaikan dan berusaha untuk mengurangi kasus kekerasan pada anak. Hal ini memperlihatkan perlunya kerjasama untuk pemenuhan kebutuhan dasar yang sesuai 
Jurnal PG-PAUD Trunojoyo : Jurnal Pendidikan dan Pembelajaran Anak Usia Dini, Volume 8, Nomor 1, April 2021 hal 8 - 14, ISSN : 2528-3553 (online), ISSN: 2407-4454 (print)

dengan hak anak, seperti pendidikan dan kesehatan. Hal itu juga memberikan suatu inspirasi pihaknya dengan Dinas Pendidikan Provinsi untuk lebih memperhatikan tentang bullying. Beliau juga mengatakan ingin menciptakan sekolah ramah anak. Sekolah Ramah anak yang dilengkapi dengan suatu proses belajar yang menyenangkan bagi anak, adanya proses bertukar ilmu yang sangat, dan jauh dari kata kekerasan fisik dan psikis pada anak.

Berdasarkan masalah di atas maka dapat menimbulkan rasa tidak aman bagi para peserta didik maupun orang tua. Sehingga diperlukan keadaan sekolah yang aman dan nyaman bagi anak, jauh dari tindak kekerasan, diskriminasi maupun bullying. Seperti yang telah dijelaskan oleh Komesioner KPAI bidang Pendidikan Retno Listyarti, Kementrian Pendidikan telah membuat program Sekolah Ramah Anak (SRA) sebagai suatu tindakan preventif yang dapat mengatasi suatu masalah yang terkait dengan pelanggaran hak-hak pada anak, Sekolah ramah anak ini bertujuan untuk pencegahan tindak kekerasan pada anak yang terjadi saat proses mengasuh dan saat pembelajaran sehingga lebih menekankan untuk memberikan konsep saling menghargai, memberikan perlindungan serta pemenuhan hak-hak anak dengan bentuk sekolah ramah anak dan dalam pengaplikasian diharapkan mendahulukan prinsip untuk melindungi anak.

Dinas Pendidikan Kabupaten Bangkalan menargetkan minimal tiga sekolah di setiap kecamatan menerapkan program SRA tersebut. TK YKK 1 Bangkalan merupakan salah satu Sekolah Taman Kanak-kanak yang yang ditunjuk menjadi rintisan Sekolah Ramah Anak (SRA) di Kabupaten Bangkalan. Adapun visi TK YKK 1 Bangkalan yakni "Generasi yang Cerdas, Kreatif, Mandiri, Berprestasi serta Berakhlak Mulia". Kepala sekolah TK YKK 1 Bangkalan mewujudkan Sekolah Ramah Anak (SRA) melalui fasilitas-fasilitas yang telah disediakan oleh sekolah, seperti kantin sehat, tempat bermain yang aman untuk anak, lingkungan sekolah yang aman dan nyaman (ada security), ruang kelas yang bersih, kegiatan belajar mengajar yang sesuai dengan kurikulum 2013 serta ekstrakurikuler ramah lingkungan (daur ulang sampah/barang bekas).

Berdasarkan uraian di atas, maka peneliti ingin mengetahui peran guru dapat melaksanakan pembelajaran yang menyenangkan jauh dari kekerasan maupun diskriminasi, bullying atau pemberian hukuman yang tidak baik terhadap peserta didik, dengan memperhatikan peran guru sebagai fasilitator, pembimbing, dan motivator dalam melaksanakan program sekolah ramah anak. Sehingga penelitian ini diberi judul "Peran Guru dalam Penerapan Sekolah Ramah Anak di TK YKK 1 Bangkalan".

\section{METODE}

Metode penelitian pada penelitian ini menggunakan penelitian kualitatif. Tujuan penelitian ini menggunakan penelitian kualitatif agar peneliti dapat mendeskripsikan sebuah fenomena yang terjadi seperti peran guru di sekolah ramah anak. Penelitian ini menggunakan metode penelitian kualitatif deksriptif, karena untuk menggali fenomena yang terjadi di lapangan dan menggambarkan secara apa adanya sesuai dengan fakta-fakta yang ada yang hanya bisa dijabarkan dengan tulisan maupun kata-kata tanpa adanya pengukuran.

Sumber data pada penelitian ini menggunakan sumber data primer dan sumber data sekunder. Adapun sumber data primer pada penelitian ini adalah hasil wawancara terhadap kepala sekolah TK YKK 1 Bangkalan. Di sisi lain, sumber data sekunder pada penelitian ini ialah berupa dokumen-dokumen maupun referensi-referensi yang menjadi panduan dalam penelitian peran guru dalam menerapkan sekolah ramah anak. 
Jurnal PG-PAUD Trunojoyo : Jurnal Pendidikan dan Pembelajaran Anak Usia Dini, Volume 8, Nomor 1, April 2021 hal 8 - 14, ISSN : 2528-3553 (online), ISSN: 2407-4454 (print)

Teknik pengumpulan data pada penelitian ini menggunakan observasi, wawancara, dan dokumentasi. Observasi awal dilakukan oleh peneliti untuk melihat permasalahan yang ada sehingga dapat digunakan sebagai bahan penelitian. Wawancara dilakukan kepada guru, kepala sekolah, dan wali murid sebagai informasi dalam penelitian ini utamanya mengenai peran guru sebagai fasilitator, pembimbing dan motivator pada sekolah ramah anak di TK YKK 1 Bangkalan. Instrumen pada wawancara dibuat berdasarkan indikator pada sekolah ramah anak. Pengambilan dokumentasi dilakukan peneliti sebagai tambahan bukti nyata tentang penelitian ini.

Analisis data pada penelitian ini dilakukan melalui tahapan reduksi data, penyajian data, kemudian kesimpulan. Penelitian ini menggunakan analisis kualitatif deskriptif, dimana penulis menguraikan secara naratif mengenai peran guru dalam penerapan sekolah ramah anak yang didukung dengan bukti-bukti hasil wawancara dan dokumentasi yang telah dilakukan peneliti. Peneliti memiliki kesimpulan awal yang masih bersifat sementara, da nada kemungkinan untuk berubah, sehingga jika ditemukan beberapa data-data-data baru yang mendukung penelitian. Penenliti memiliki kesimpulan yang kredibel jika peneliti kembali ke lapangan selama beberpa kali dengan data yang konsisten, maka kesimpulan awal yang ada dapat menjadi kesimpulan yang kredibel. Uji kredibilitas menggunakan triangulasi. Triangulasi yang digunakan dalam penelitian ini adalah triangulasi sumber data dan triangulasi teknik pengumpulan data. Pada triangulasi sumber data, peneliti membandingkan informasi dari sumber data primer (peranan guru dalam sekolah ramah anak) dengan sumber data sekunder (dokumentasi, laporan hasil perkembangan). Sedangkan pada triangulasi teknik pengumpulan data, peneliti membandingkan hasil pengamatan dengan hasil wawancara.

\section{HASIL DAN PEMBAHASAN}

Sekolah ramah anak merupakan salah satu program pemerintah untuk diterapkan pada sekolah-sekolah dengan tujuan mengurangi angka kekerasan maupun diskriminasi pada anak. Pada sekolah ramah anak, guru/pendidik menjadi salah satu komponen yang sangat penting. Guru adalah tonggak utama dalam pembelajaran karena guru berinteraksi secara langsung dan memberikan pengaruh kepada peserta didik. Guru merupakan suatu model yang dijadikan panutan dan harus memiliki beberapa kompetensi tidak hanya secara pedagogis, akan tetapi juga memiliki kepribadian dan jiwa sosial.

Proses pembelajaran sangat memerlukan kehadiran seorang guru yang profesional, karena posisi guru tidak akan tergantikan oleh teknologi sehingga peran guru akan tetap diperlukan. Dalam proses pembelajaran guru mempunyai peranan yang sangat penting.

Peran guru di TK YKK 1 Bangkalan memiliki kedudukan yang sangat penting, karena guru berada di garis depan yang mana guru secara langsung berhadapan dengan anak. Guru juga menjadi orang tua kedua bagi anak saat di sekolah, oleh karenanya peran guru sangat berpengaruh pada keberlangsungan anak untuk kedepannya.

Terdapat berbagai macam peran yang harus dimainkan oleh guru di sekolah, diantaranya yaitu peran guru sebagai fasilitator. Guru TK YKK 1 Bangkalan memberikan fasilitas kepada anak yang sesuai dengan program sekolah ramah anak. Guru merancang dan menyediakan media pembelajaran yang ramah anak dengan menggunakan bahan dari barang bekas, yang mana media tersebut aman bagi anak. Guru melakukan komunikasi dan interaksi dengan anak dari awal masuk sekolah hingga pada saat anak akan pulang sekolah. Di tiap masing-masing kelas telah tersedia alat permainan edukatif untuk anak. Agar pembelajaran dapat menarik TK YKK 1 Bangkalan juga menyiapkan ruang outdoor untuk kegiatan belajar dan 
Jurnal PG-PAUD Trunojoyo : Jurnal Pendidikan dan Pembelajaran Anak Usia Dini, Volume 8, Nomor 1, April 2021 hal 8 - 14, ISSN : 2528-3553 (online), ISSN: 2407-4454 (print)

bermain. Kegiatan pembelajaran outdoor misalnya kegiatan tentang sains yaitu tentang tanaman.

Peran guru sebagai pembimbing, yaitu guru dituntut untuk mampu melakukan perencanaan yang baik, dan implementasi ilmu dengan keterlibatan peserta didik, sehingga dapat mengarahkan peserta didik sesuai dengan tujuan pembelajaran. Guru TK YKK 1 Bangkalan memberlakukan kebiasaan peduli dan berbudaya lingkungan, dimana hal tersebut disesuaikan dengan kurikulum ramah anak yang berlaku di TK YKK 1 Bangkalan yaitu mengacu pada sosial budaya. Kegiatan yang dilakukan yaitu mengenalkan budaya-budaya yang ada di Bangkalan. Sekolah juga menerapkan di setiap tanggal 24 pada setiap bulannya untuk memakai baju tradisional Madura. Hal-hal yang berkaitan dengan budaya daerah sebisa mungkin guru perkenalkan kepada anak, termasuk bahasa Madura itu sendiri. Mengingat karakteristik anak usia dini yaitu belajar sambil bermain, maka guru juga mengajarkan permainan tradisional kepada anak. Pada kegiatan peduli lingkungan, guru mengajak anak untuk melakukan go green atau penghijauan dengan menanam tanaman di sekolah bersama dengan orang tua masing-masing. Berbagai kegiatan mengenai budaya dan lingkungan guru terapkan kepada anak agar anak memiliki pengalaman belajar yang beragam, serta dapat mengarahkan dan membimbing anak untuk lebih peduli terhadap budaya sendiri serta lingkungan di sekitar.

Guru sebagai motivator, tergambar ketika guru dapat menciptakan suasana belajar yang menyenangkan dan nyaman untuk anak sesuai dengan sekolah ramah anak. Seperti melibatkan anak secara langsung dalam kegiatan belajar agar suasana belajar dapat hidup dan menyenangkan untuk anak. Guru memotivasi anak yang malas belajar dengan melakukan pendekatan kepada anak, kemudian memberikan pujian ataupun hadiah jika anak tersebut bersedia mengikuti arahan guru. Kepala TK YKK 1 Bangkalan juga, mengingatkan pada semua guru untuk bisa memotivasi anak dengan menjaga mood anak agar tetap baik selama di sekolah, agar anak masuk sekolah dengan keadan yang gembira dan tidak merasa tertekan.

Dalam menerapkan sekolah ramah anak, ada beberapa indikator yang harus dilaksanakan, yaitu mengenai kebijakan sekolah ramah anak, pelaksanaan kurikulum, pendidik dan tenaga pendidik yang terlatih, sarana dan prasarana, serta partisipasi orang tua maupun masyarakat (KPAI, 2016).

TK YKK 1 Bangkalan telah menerapkan sekolah ramah anak yang sesuai dengan indikator sekolah ramah anak. Mulai dari kebijakan sekolah ramah anak yang telah memenuhi Standar Pelayanan Minimal (SPM) di Satuan Pendidikan. Adapun SPM yang sudah ada adalah SPM kesehatan untuk penjaringan kesehatan, adanya anti kekerasan yang diterapkan semua warga sekolah termasuk orang tua. Kemudian pengembangan kurikulum yang telah sesuai dengan program sekolah ramah anak, yaitu tersedianya RPP (Rencana Pelaksanaan Pembelajaran) yang ramah anak, serta penataan lingkungan kelas yang menunjang suasana pembelajaran yang aktif dan ramah bagi pembelajaran. Adanya partisipasi masyarakat dan orang tua dalam menerapkan sekolah ramah anak di TK YKK 1 Bangkalan. Partisipasi yang diberikan orang tua yaitu dengan memberikan persetujuan setiap kegiatan anak yang sesuai dengan konsep sekolah ramah anak seperti ikut serta dalam kegiatan parenting di sekolah. Partisipasi yang diberikan masyarakat yaitu mendukung upaya penerapan prinsip-prinsip sekolah ramah anak dengan memberi akses kepada anak dan guru untuk karyawisata, kegiatan seni, dan budaya. Kesesuaian konsep lingkungan sekolah yang mendukung program sekolah ramah anak, yaitu penggunaan konsep ramah lingkungan dengan 
Jurnal PG-PAUD Trunojoyo : Jurnal Pendidikan dan Pembelajaran Anak Usia Dini, Volume 8, Nomor 1, April 2021 hal 8 - 14, ISSN : 2528-3553 (online), ISSN: 2407-4454 (print)

menggunakan bahan bekas sebagai media pembelajaran.

Berdasarkan pemaparan diatas, peran guru dalam penerapan sekolah ramah anak di TK YKK 1 Bangkalan sudah sesuai dengan indikator sekolah ramah anak. Terbukti dari hasil observasi dan wawancara yang dilakukan oleh peneliti kepada pihak-pihak yang bersangkutan. Guru dan pihak sekolah saling bekerjasama dalam mewujudkan sekolah ramah anak dengan menerapkan pembelajaran yang aman, nyaman, dan berbudaya.

\section{SIMPULAN DAN SARAN}

Peran guru di TK YKK 1 Bangkalan yang meliputi peran guru sebagai seorang yang dapat memfasilitasi proses pembelajaran, sebagai pembimbing dari peserta didik, sebagai motivator yang dapat menangkap motivasi anak saat lemah, sesuai dengan program sekolah ramah anak. Kebijakan sekolah yang sesuai dengan sekolah ramah anak dapat memberikan dampak positif kepada anak, dimana anak mendapatkan pengalaman belajar yang berbeda dengan menggunakan acuan sosial budaya pada kurikulumnya.

DAFTAR PUSTAKA

Aqib, Z. (2008). Sekolah Ramah Anak Mencegah Kekerasan dalam Sekolah. Bandung: Yrama Widya.

Fadlilah, M. (2012). Desain Pembelajaran PAUD. Jogjakarta: Ar-Ruzz Media.

Husain, L. (2017). Profesi Keguruan Menjadi Guru Profesional. Yogyakarta: Pustaka Baru Press.
KPAI. (2016). Panduan Sekolah dan Madrasah Ramah Anak. Jakarta: Erlangga.

Lingkar Jatim. (2019). Peringati Hari Anak Nasional 2019, Bupati Bangkalan Terbitkan SK KLA. Diakses pada 26 Maret 2020, dari

https://lingkarjatim.com/madur a/bangkalan/peringati-hari-ana k-nasional-2019-bupati-bangka lan-terbitkan-sk-kla.

Moleong, Lexy. J. (2018). Metodologi Penelitian Kualitatif Edisi Revis. Bandung: PT. Remaja Rosdakarya.

Naim, Ngainun. (2012). Character Building: Optimalisasi Peran Pendidikan dalam Pengembangan Ilmu \& Pembentukan Karakter Bangsa. Jogjakarta: Ar-Ruz Media.

Pedoman Pendidikan Ramah Anak dari Asdep Pemenuhan Hak Pendidikan Anak, Deputi Tumbuh Kembang Anak, Kementrian Pemberdayaan Perempuan dan Perlindungan Anak.

Sanjaya, Wina. (2016). Strategi Pembelajaran Berorientasi Standar Proses Pendidikan. Jakarta: Prenadamedia Group

Sugiyono. (2020). Metode Penelitian Kualitatif untuk Penelitian yang Bersifat Eksploratif, Enterpretif, Interaktif, dan Konstruktif. Bandung: ALFABETA.

Undang-undang Republik Indonesia

Nomor 14 Tahun 2005 Tentang Guru dan Dosen. 